Copyright by the Ecological Society of America.

This is an electronic version of an article published as: Dudas, S.E., Dower, J.F., \& Anholt, B.R. (2007). Invasion dynamics of the varnish clam (Nuttallia obscurata): A matrix demographic modeling approach. Ecology, 88(8), 2084-2093. DOI: 10.1890/06-1216.1

Ecology is published by the Ecological Society of America and is available online at: http://esajournals.onlinelibrary.wiley.com/hub/journal/10.1002/(ISSN)1939-9170/ and this article is available at: http://onlinelibrary.wiley.com/doi/10.1890/06-1216.1/full. 


\title{
INVASION DYNAMICS OF THE VARNISH CLAM (NUTTALLIA OBSCURATA): A MATRIX DEMOGRAPHIC MODELING APPROACH
}

\author{
Sarah E. Dudas, ${ }^{1,3}$ John F. Dower, ${ }^{1,2}$ and Bradley R. Anholt ${ }^{1}$ \\ ${ }^{1}$ Department of Biology, University of Victoria, Victoria, British Columbia V8W3N5 Canada \\ ${ }^{2}$ School of Earth and Ocean Sciences, University of Victoria, Victoria, British Columbia V8W3N5 Canada
}

\begin{abstract}
Marine invaders have become a significant threat to native biodiversity and ecosystem function. In this study, the invasion of the varnish clam (Nuttallia obscurata) in British Columbia, Canada, is investigated using a matrix modeling approach to identify the life history characteristics most crucial for population growth and to investigate population differences. Mark-recapture analyses and field collections from 2003 to 2004 were used to determine individual growth, survival rates, and fecundity for two sites. A multi-state matrix model was used to determine population growth rates and to conduct sensitivity and elasticity analyses. A life table response experiment was also used to determine what life history stage contributed most to observed differences in population growth rates. Population survey data were used in conjunction with the matrix model to determine plausible recruitment levels and to investigate recruitment scenarios. Both populations are currently declining but are likely sustainable because of the pulsed nature of large recruitment events. Survival of larger clams $(>40 \mathrm{~mm})$ is the most important for population growth based on elasticity and sensitivity analyses. Adult survival also had the largest influence on observed differences between sitespecific population growth rates. The two populations studied differed in recruitment dynamics; one experiencing annual recruitment with higher post-settlement mortality and the other, episodic recruitment and lower post-settlement mortality. The most influential factor for the successful invasion of the varnish clam appears to be survival of the larger size classes. Therefore, any process that decreases adult survival (e.g., predation, commercial harvest) will have the greatest impact on population growth.
\end{abstract}

Key words: marine invasion ecology; matrix model; Nuttallia obscurata; population growth; recruitment; survival; varnish clam.

\section{INTRODUCTION}

The number of invasions by non-indigenous marine invertebrate species in the Pacific Northwest has increased steadily over the last few decades, posing a threat to native biodiversity and ecosystem function (Wonham and Carlton 2005). Because many marine invertebrates have complex life cycles that include both benthic and pelagic stages, once an invader has established it becomes almost impossible to prevent further spread of the species. Identifying the life history characteristics that contribute to invasion success is crucial to understanding why only some invaders succeed (i.e., establish abundant, sustainable populations), or are more successful, and for identifying species that may be poised to invade, and which might exert the greatest impacts.

Although matrix demographic analysis has long been a popular tool in population and community ecology, including studies of marine systems (Crouse et al. 1987,

Manuscript received 18 July 2006; revised 7 December 2007; accepted 3 January 2007. Corresponding Editor: E. D. Grosholz.

3 Present address: Department of Zoology, Oregon State University, 3029 Cordley Hall, Corvallis, Oregon 97331 USA. E-mail: sdudas@canada.com
Levin and Caswell 1987, Gotelli 1991, Pascual and Caswell 1992, Nakaoka 1997, Miller 2001, Davis and Levin 2002), only recently has its use been extended to study invasion dynamics (Shea and Kelly 1998, Marco and Paez 2000, Neubert and Caswell 2000, Parker 2000, Ruesink 2003, Buhle et al. 2005, Govindarajulu et al. 2005). This approach enables one to determine vital population characteristics such as population growth rate, stable size distribution, and reproductive contribution (Nakaoka 1997). In a size-structured matrix, the importance of the different life history stages for total population growth can be determined using sensitivity and elasticity analyses. These analyses determine the total (sensitivity) and proportional (elasticity) contributions of each life history stage and vital rate (i.e., reproduction, growth, survival) to population growth. Life table response experiments can also be conducted to investigate the response of a species life table (or set of vital rates) to experimental treatments (Caswell 2001), different habitats, or harvesting regimes (Miller 2001).

In this study, we investigate the invasion of the varnish clam (Nuttallia obscurata) in coastal British Columbia, Canada (BC). We use capture-mark-recapture methods to determine growth and survival rates, along with field collections to determine size-dependent reproductive contributions, and combine these data in a 
multi-state matrix demographic model. The varnish clam (Nuttallia obscurata; Reeve 1857) was first reported in the Pacific Northwest in Semiahmoo Bay (Washington), near Vancouver BC in 1991 (Forsyth 1993). Originally native to Korea, China, and southern Japan, the varnish clam is suspected to have been introduced to coastal BC via ballast water disposal in Vancouver Harbor (Gillespie et al. 1999). Since its introduction the varnish clam has spread rapidly throughout $\mathrm{BC}$ and the U.S. Pacific Northwest, attaining adult densities of up to 800 clams $/ \mathrm{m}^{2}$ (Dudas 2005). The impacts of this invasion are still largely unknown. The varnish clam serves as a new prey source for many local predators, particularly crabs that show preference for the invader over local species when burial depth is limited (Dudas et al. 2005). High densities of invader prey have the potential to increase predator populations (Byers 2005) and could impact local communities. Furthermore, the high densities the varnish clam attains and large populations are likely to impact the physical and chemical composition of the sediment and nutrient fluxes although this has not yet been studied.

Understanding the life history characteristics most influential in the varnish clam invasion is crucial for determining the reasons for its success and assessing future impacts. Life table response experiments can be used to examine differences between invader populations and observe how they vary spatiotemporally. For marine invertebrate invaders with both a benthic and pelagic life history stage matrix analyses can also be used to assess the importance of pre- (e.g., larval supply) and post-settlement processes (e.g., predation) to recruitment to adult populations and subsequent population growth (i.e., by observing how sensitive population growth rates are to changes in recruitment). Annual varnish clam population surveys (Dudas 2005) indicate that population size-structure and recruitment vary between populations in coastal BC. Within this context of population survey information, matrix demographic analysis can be used as a tool to investigate the recruitment levels necessary to create the annual length-frequency distribution observed. The main goals of our analyses were to (1) determine which life history stage(s) is most crucial to population growth, (2) compare the growth rates of two populations and determine which life history stage(s) contributed to observed differences, (3) conduct population projections to investigate the plausibility of different recruitment scenarios, and (4) determine how these various factors affect population dynamics.

\section{Methods \\ Study site}

Capture-mark-recapture studies were conducted at two sites in British Columbia, Canada. One site was located in Bamberton Provincial Park (hereafter referred to as Bamberton; $48^{\circ} 36^{\prime} 20^{\prime \prime}$ N, 123 $31^{\prime} 14^{\prime \prime}$ W) in Saanich Inlet on the east site of Vancouver Island, Canada, while the other was located at Robbers Passage (48 $53^{\prime} 48^{\prime \prime} \mathrm{N}$, $125^{\circ} 7^{\prime} 14^{\prime \prime} \mathrm{W}$ ), in Barkley Sound on the west coast of Vancouver Island. Bamberton is a protected beach that was likely invaded shortly after the initial introduction near Vancouver (first record in 1994 [Merilees and Gillespie 1995]). Robbers Passage is a more exposed site several hundred kilometers away, and presumably the result of a more recent invasion (first record in 2000).

\section{Field methods}

Mark-recapture methods were used to calculate growth and survival rates of the varnish clam populations at Robbers Passage and Bamberton. Approximately 600 clams ranging in size from 10 to $65 \mathrm{~mm}$ were marked at each site in May 2003 (using permanent ink markers and then sealed with cyanoacrylate glue). Clams $\geq 30 \mathrm{~mm}$ in length were marked and reburied in the field on the same day. Clams $<30 \mathrm{~mm}$ in length were too time-consuming to mark during one low tide. Therefore the clams were marked in the lab, placed in flowing seawater once the marks had dried, and then returned to the field the following day. Mark-recapture plots (one at each site) were approximately $4 \times 1 \mathrm{~m}$ in size, situated between 1.6 and $1.8 \mathrm{~m}$ above chart datum. Clams were recaptured and their growth increments measured (to the nearest millimeter) in September and May of each year until 2005. Large clams were recaptured by carefully digging the mark-recapture plot with hand spades. Small clams (i.e., $<30 \mathrm{~mm}$ ) were excavated by hand and the substratum was sieved to 2 $\mathrm{mm}$ to ensure that very small clams were not missed.

Annual population survey data were available for Robbers Passage from 2001 to 2003 and from Bamberton for 2003 from our previous studies (Dudas 2005; Appendix: Fig. A1). Monthly length-frequency distributions from both sites were available from May 2002 to January 2004 (Dudas 2005). Length-frequency data were collected via similar methods to the markrecapture data. The two. sites appear to differ in recruitment dynamics; Robbers Passage having extremely low annual recruitment (or more episodic recruitment pulses), and Bamberton having higher levels of regular annual recruitment (Dudas 2005). The sites also differ oceanographically, with Robbers Passage typically experiencing cooler temperatures (Dudas and Dower 2006) and more wave exposure than Bamberton. Robbers Passage is also a smaller beach, approximately one-fifth the size of Bamberton, and its varnish clam density is only half as high.

\section{Survival and growth transition rate analysis}

Survival and growth transition rates were determined using capture-mark-recapture (CMR) methods (Lebreton et al. 1992) implemented in the software program MARK (White and Burnham 1999). In CMR analysis, live recaptures can be used to determine survival and recapture rates using the Cormack-Jolly-Seber (CJS) model. The CJS model assumes that (1) all individuals 


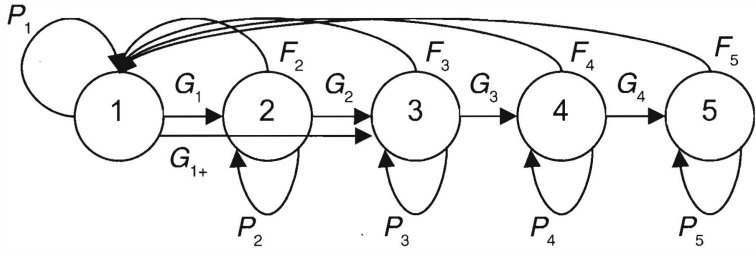

FIG. 1. Life cycle graph for the varnish clam (Nuttallia obscurata) transition matrix. Key: $G_{i}$, probability of surviving and growing to size class $i+1$ in one year (size class 1 also includes the probability of growing $i+2,1 \rightarrow 3$ ); $P_{i}$, probability of surviving and remaining in size class $i$ in one year; $F_{i}$, reproductive contribution of size class $i$.

have the same probability of recapture, (2) all individuals in the same size class have the same probability of survival from one interval to the next, (3) marks are not lost between captures or missed during recapture, and (4) all samples are instantaneous and each release is made immediately after sampling (Pollock et al. 1990). Deviations from these assumptions can lead to overdispersion. We tested for overdispersion using the bootstrap routine in MARK using a fully size- and time-dependent model for each site (using two size classes, $<30 \mathrm{~mm}$ and $\geq 30 \mathrm{~mm}$, for each site). More than 500 bootstrap simulations were conducted to determine the overdispersion factor, $\hat{c}$, for each population separately and then $\hat{c}$ was used to adjust the variances and confidence intervals to account for this overdispersion (Burnham and Anderson 1998).

The CJS model can be expanded to include a growth parameter to examine how individuals move between size classes (Brownie et al. 1993). The multi-state CMR model was used to investigate size, site, and time dependence in survival rates, recapture rates, and growth transition rates. Although goodness-of-fit tests are being developed for this type of model (Pradel et al. 2003), they are not yet well established. Therefore, the averaged $\hat{c}$ values from the bootstrap simulations of each separate population were used to adjust the CMR model parameter estimates (e.g., survival, recapture, growth transition) to account for overdispersion, resulting in conservative tests of hypotheses.

The global model (i.e., containing all the parameters thought to influence survival, recapture, and growth transitions) included full time dependence in survival, recapture, and growth transition for each size class and site. Because clams can only grow from one size class to the next (i.e., they cannot shrink), all other transition parameters were set to zero. The first step with the global model was to determine whether the influence of site had a consistent (additive) effect over time. Simplified versions of the global model (i.e., in which one or more parameters were constant) were then used to investigate differences in survival, recapture, and growth transitions between sites. QAIC values (AIC modified to account for overdispersion) and $\triangle \mathrm{QAIC}$ were used to assess model fit. $\triangle$ QAIC values were also used to calculate Akaike weights to calibrate the models and provide a measure of "relative plausibility" (Burnham and Anderson 1998).

\section{Matrix model}

Deterministic size-class matrix models were developed for each site. Five size classes were chosen based on sizedependent differences in survival and fecundity. Transitions between size classes were described in a transition matrix (A) and projected according to the following equation (Caswell 2001):

$$
\mathbf{n}(t+1)=\mathbf{A} \times \mathbf{n}(t)
$$

where $\mathbf{A}$ is a matrix of $a_{i j}{ }^{\prime} \mathbf{s} ; \mathbf{n}(t)$ is size-class abundance at time $t ; \mathbf{n}(t+1)$ is size-class abundance at time $t+1$; and $a_{i j}$ represents the transition probability of size class $i$ to size class $j$ through growth, survival, and fecundity to the next time step. The time-step for both sites was one year. The $a_{i j}$ 's, of the matrix (including fecundity, growth, and survival) are shown as a life-cycle graph in Fig. 1.

Population census is assumed to occur after reproduction. Therefore, $F$ represents the number of fertilized eggs multiplied by a recruitment rate (i.e., the probability of survival from fertilization to a size large enough to be detected in population surveys, $\sim 15 \mathrm{~mm}$ ). To calculate the reproductive contribution, $F$, for each size class, we used site and size-specific fecundity (i.e., number of eggs per clam) and sex ratios from previous observations (Dudas and Dower 2006; Appendix: Fig. A2) multiplied by a conservative fertilization rate of $50 \%$ based on literature values (Grant et al. 1998, Marshall et al. 2004) and a recruitment rate: $F=($ sex ratio $\times$ fecundity $\times 0.50) \times($ recruitment rate) . For recruitment rates, literature values were used as a starting point. Bivalve studies report highly variable (but universally low) recruitment rates with only $0.001-0.0001 \%$ of larvae reaching settlement (Brousseau 1978), and only 0.001-0.0001 recruits per egg spawned -(Beukema et al. 1998). To determine a realistic recruitment estimate the population was projected by one year using the transition matrix and a range of recruitment rates $(1 \times$ $10^{-5}$ to $\left.1 \times 10^{-9}\right)$. The predicted size distribution from the one year projection was then compared to the observed length-frequency distributions. Because annual population surveys were also conducted at Robbers Passage and Bamberton we used this information to construct more precise estimates of recruitment at this site (see Brousseau and Baglivo [1982] for a similar approach). We determined the recruitment rate that minimized the differences between the observed sizeclass distributions and the predicted size-class distributions based on the transition matrix, using the SOLVER routine in Excel (Microsoft, Redmond, Washington, USA), which uses a nonlinear optimization code. In a separate run of the matrix model, SOLVER was also used to vary both the growth transition $(G)$ and the survival $(P)$ rates at Robbers Passage to investigate the 
influence of uncertainty or variation in these estimates. This enabled us to examine how changes in observed growth transition and survival rates would influence the sensitivities and elasticities from the matrix model. SOLVER was used to obtain the growth transition and survival rates that minimized the combined differences (i.e., for 2002 and 2003) between observed and predicted size-class distributions.

Because the varnish clam has a planktonic larval stage and a benthic adult stage adult population dynamics may be decoupled from larval dynamics, with local fecundity exerting only minor effects on population growth and recruitment (Hughes 1990). For this study, we assumed that the reproductive contribution of the adults (based on the site-specific adult fecundities and sex ratios, and the assumed fertilization and recruitment rates) is representative of the contribution from all larval sources (i.e., both local and regional) from which the population receives recruits. Because we were able to use field observations of population size structure and density to estimate local recruitment levels (as part of the reproductive contribution, $F$ ) we feel this is a realistic assumption in this case. Violation of this assumption will have greater impacts on the population growth rate values obtained by this model if the sensitivity and elasticity values for the reproductive contribution are high.

To investigate seasonal differences in survival and growth, time intervals in MARK were set to calculate summer (May-September) and winter (October-April) survival, recapture, and growth transition rates. Survival rates were partitioned into those that survived and grew to the next size class $(G=$ survival rate $\times$ growth transition rate) and those that survived but remained in the same size class $(P=$ survival rate $\times(1-$ growth transition rate)).

For the matrix model (with a one-year time-step projection) yearly growth $(G)$ and survival $(P)$ values were calculated by eliminating time dependence in the multi-state CMR model. Because all size class 1 clams from Robbers Passage grew to size class 3 in one year, the yearly growth transition from 1 to 2 in this model actually represents the number of individuals that grew from size class 1 to size class 3 . The clams that transition from size class 1 to size class 3 are also accounted for in the size class 2-3 growth transition estimates in the yearly time intervals in MARK. Therefore, the size class 2-3 growth transition estimates include clams that grew from size class 1 to 3 in addition to those that grew from size class 2 to 3 . To account for this influence in the $2-3$ size-class growth transition rate, the number of size class 1 clams was determined from the raw data and subsequently removed from the $2-3$ growth transition rate used in matrix calculations. This correction adjusts the 2-3 size-class growth transition rate so that it represents only those that started in size class 2 at the beginning of the study period (as in all other size classes).

Sensitivity analysis demonstrates how changes in the matrix elements $a_{i j}$, affect the population growth rate.
High sensitivity of a vital rate implies that even a small change in its value has a large effect on the population growth rate (Horvitz and Schemske 1995). High elasticity implies that the vital rate in question has a high proportional contribution to the change in population growth rate, for a given proportional perturbation of that rate. Sensitivities and elasticities were calculated for all matrix elements (i.e., $F, P$, and $G$ ) and combined to determine the total sensitivity and elasticity for each size class. This analysis was done separately for each site.

Confidence intervals (95\%) for sensitivities and the asymptotic population growth rate were determined by generating 1000 matrices, where matrix elements were drawn from a normal distribution, with mean and variance from the logit transformed estimates from CMR analysis (i.e., $G$ and $P$ ). To investigate the consequence of error in the fecundity estimates we added variance to reproductive contribution $(F)$ by setting the standard deviation to $50 \%$ of the mean, which is similar to that observed for fecundity. A gamma function was used to generate random deviates with mean and standard deviations to match the generated estimates of the reproductive contribution.

To compare the population growth rates from Robbers Passage and Bamberton, we conducted a life table response experiment. An average matrix of the sites was compared to the matrix of each site individually, and the differences in the population growth rates were decomposed into the contributions from each vital rate/matrix element (Davis and Levin 2002). This approach allowed us to determine which matrix elements are responsible for observed differences in population growth rates (Caswell 2001, Davis and Levin 2002).

Because the time since invasion is relatively short, most invader populations may not have achieved a stable size distribution. The rate of convergence to this distribution, the damping ratio (Caswell 2001), is determined by the ratio of the dominant eigenvalue to the first subdominant eigenvalue. The larger the damping ratio, the faster the population is converging toward its stable size distribution. If a population is far from achieving this stable distribution it may exhibit transient behavior (Horvitz and Schemske 1995) in population growth rate and sensitivities that may differ from asymptotic behavior. Therefore, it is not clear how well analytical results (e.g., sensitivities, elasticities) will represent population dynamics for populations that have not reached the stable size distribution (Parker 2000). We used an index of proportional similarity (PS) to measure similarity between the observed size distributions and the stable size distribution (Horvitz and Schemske 1995). This index was also used for the recruitment scenarios to measure the similarity between observed size distributions and the predicted size distributions from the matrix model projection. All analyses were conducted using MATLAB (Mathworks, 
TABLE 1. Factors included in multi-state models for capture-mark-recapture analysis adjusting for overdispersion, with corresponding deviance and Akaike values.

\begin{tabular}{|c|c|c|c|c|c|c|c|}
\hline Survival & Recapture & Transition & $K$ & QDev & QAIC & $\triangle \mathrm{QAIC}$ & $w$ \\
\hline Site + time & site $\times$ time & site $\times$ time & 57 & 112 & 3332 & 0 & 0.87 \\
\hline Site + time & site & site $\times$ time & 56 & 118 & 3336 & 4 & 0.13 \\
\hline Time & site $\times$ time & site $\times$ time & 51 & 142 & 3350 & 17 & 0.00 \\
\hline Site + time & constant & site $\times$ time & 51 & 142 & 3350 & 18 & 0.00 \\
\hline Site + time & time & site $\times$ time & 57 & 134 & 3355 & 23 & 0.00 \\
\hline Constant & site $\times$ time & site $\times$ time & 44 & 166 & 3360 & 27 & 0.00 \\
\hline Site + time & site $\times$ time & time & 56 & 282 & 3501 & 168 & 0.00 \\
\hline
\end{tabular}

Notes: Models are ordered according to goodness-of-fit; + and $\times$ symbols denote additive and interactive factors, respectively. The overdispersion factor is $\hat{c}=1.61$ ); $K$ is the number of parameters (including survival, recapture, and growth transition rates); QDev is adjusted deviance; QAIC is Akaike Information Criterion values; $\triangle$ QAIC is AIC value differences; and $w$ is AIC weight.

Natick, Massachusetts, USA) and the PopTools add-in for Microsoft Excel (available online). ${ }^{4}$

\section{Recruitment scenarios}

The annual length-frequency distributions from Robbers Passage from 2001 to 2003 showed a distinct pulse of recruitment in 2002 (Dudas 2005). To examine the influence of pulsed recruitment on size-class abundance, the population was projected for two years using varying transition matrices, alternating years of zero recruitment with a range of recruitment rates $\left(1 \times 10^{-6}\right.$ $9 \times 10^{-8}$ ). The observed length-frequency distributions from 2002 and 2003 were then compared with the predicted distributions using the proportional similarity (PS) index.

\section{RESULTS}

\section{Capture-mark-recapture model}

Model selection showed that survival, recapture, and growth transitions were all size, site, and time dependent, with the effects of site and time being additive for survival (i.e., one site consistently has higher or lower survival over time for a size class; Table 1). Comparison of survival rates (Fig. 2A) between sites shows higher survival for clams $<30 \mathrm{~mm}$ in length at Robbers Passage and higher survival for clams $\geq 30 \mathrm{~mm}$ in length at Bamberton. Recapture rates differed slightly between sites, with higher rates at Bamberton (Fig. 2B). All growth transition estimates were higher at Robbers Passage, indicating faster growth rates at this site (Fig. 2C). For size-class 1 clams, survival was higher in the summer months and. for size classes $\geq 2$ survival rates were slightly lower (Fig. 2A). Recapture rates were variable between size class and season but were higher for size classes $\geq 3-4$. Growth transition rates were higher for size classes $\leq 2-3$ and tended to be higher in the summer months (Fig. 2C).

\section{Matrix model}

The transition matrices and associated recruitment rates used to project the populations for Robbers Passage and Bamberton are shown in Appendix: Table

\footnotetext{
${ }^{4}\langle$ www.cse.csiro.au/poptools/ $\rangle$
}

A1. Holding recruitment constant for both sites $(2 \times$ $10^{-6}$ ) yielded very different size-class abundance projections for the two beaches. Although one-year projections based on a recruitment level of $2 \times 10^{-6}$ produced a plausible size-class abundance distribution for Bamberton, this recruitment level was too high for Robbers Passage (Appendix: Fig. A3). Robbers Passage appears to experience much lower levels of recruitment than Bamberton. In fact, the recruitment rate that predicted size-class abundance most accurately for Robbers Passage was less than $5 \%$ of the recruitment at Bamberton (Appendix: Fig. A4). This recruitment level produces more plausible size-class abundances with a higher similarity for $2001-2003$ (PS $=43-48 \%$ and $87-$ $90 \%$ for recruitment levels $2 \times 10^{-6}$ and $7.4 \times 10^{-8}$, respectively). Based on these results, recruitment values of $2 \times 10^{-6}$ (Bamberton) and $7.4 \times 10^{-8}$ (Robbers Passage) were used to conduct the matrix demographic analysis.

The dominant eigenvalue $(\lambda)$ indicated that both populations are currently declining (Robbers Passage $\lambda$ $=0.73, \mathrm{CI}=0.65-0.79$; Bamberton $\lambda=0.84, \mathrm{CI}=0.78-$ 0.88 ). Adding variance to reproduction had little effect on $\lambda$ estimates $(0.04 \%$ decrease for Robbers Passage, $0.2 \%$ decrease for Bamberton). The stable size-class distributions had low similarity relative to the annual population survey size-class distributions observed for either population ( $\mathrm{PS}=35-58 \%$ for 2001-2003 for Robbers Passage, 59\% for Bamberton). The damping ratios were also low (1.34 for Robbers Passage, 1.09 for Bamberton), indicating slow convergence to the stable size-class structure.

Survival rates of the largest size classes $(40-50 \mathrm{~mm}$ and $\geq 50 \mathrm{~mm}$ ) had the highest sensitivity and elasticity values for Robbers Passage and Bamberton respectively (Fig. 3A, B, E, F [left-hand panels]). Because of these high values, the larger size classes also had the highest combined sensitivities and elasticities (Fig. 3C, D, G, H [right-hand panels]).

The life table response experiment showed that the largest difference between the two transition matrices occurred in the reproductive values $(F)$ for the $\geq 50 \mathrm{~mm}$ size class (Fig. 4A). However, site differences in the survival of the $40-50 \mathrm{~mm}$ size class had the largest 
contribution to between-site differences in population growth (Fig. 4B). Individual growth and survival rates are likely to vary temporally; therefore the influence of changes in these matrix elements on the results was investigated. To test the robustness of the sensitivities and elasticities to changes in growth and survival rates the SOLVER routine was used to vary these rates in the transition matrix to produce the most accurate size-class distribution predictions for Robbers Passage for 20012003. This produced the highest similarity between observed and predicted size-class distributions (PS = 93-94\% for 2002-2003). However, the rates that provided the best fit were unrealistic (e.g., survival rate of $100 \%$ for small size classes). Despite the changes in growth and survival rates, the larger size classes maintained their highest sensitivities and elasticities.

\section{Recruitment scenarios}

The most accurate size-class abundance predictions for Robbers Passage resulted from a scenario in which a recruitment rate in 2002 (with a recruitment level of 7.4 $\times 10^{-8}-10 \times 10^{-7}$ ) was followed by a year of zero recruitment in 2003 (Appendix: Fig. A4c, PS $=91 \%$, 2002; PS $=90 \%$, 2003). Pulsed recruitment marginally increased the similarity for 2002 (the year in which the recruitment pulse was observed), as compared to holding recruitment constant each year. However, decreasing the following year of recruitment to zero resulted in a $3 \%$ increase in the proportional similarity between observed and predicted size-class abundances for 2003. This suggests that interannual variability in recruitment at Robbers Passage is high.

\section{DisCUSSION}

Identifying the most important life history characteristics for invasion success has long been a key objective of invasion biology (Barrett and Richardson 1986, Ehrlich 1986). While characteristics such as fast growth rate, high fecundity, and a wide range of environmental tolerances (Ehrlich 1986) are likely to apply to many invaders, identifying the most crucial life history stage for specific invasions is essential for addressing conservation and mitigation concerns (Caswell 2001), and for determining where to focus future research efforts (Parker 2000). In the case of the varnish clam invasion of coastal $\mathrm{BC}$, the factor that contributes the most to population growth is the survival of the larger size classes. This finding was consistent among sites, although the sensitivity and elasticity was highest for the survival of 40-50 mm clams for Bamberton, and $\geq 50$ mm clams for Robbers Passage. The high sensitivities and elasticities corresponded to the highest survival rates at each site (i.e., 0.83 for Bamberton clams 40-50 mm, 0.72 for $\geq 50 \mathrm{~mm}$ Robbers Passage clams). Stochastic matrix models of barnacles and bivalves have shown similar results, in which population dynamics were found to be more sensitive to changes in survival than
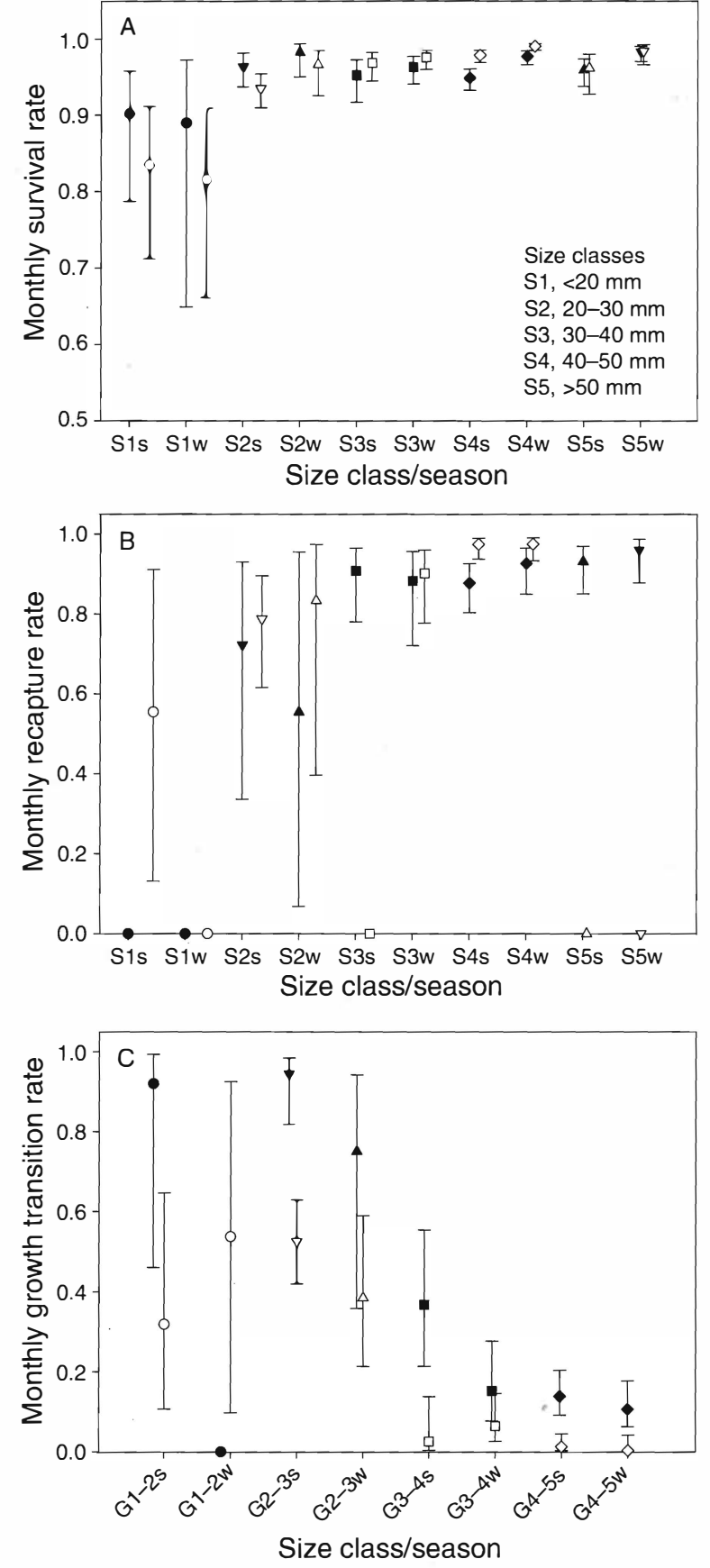

FIG. 2. Varnish clam (A) monthly survival rates, (B) recapture rates, and $(\mathrm{C})$ growth transition rates for Robbers Passage (solid symbols) and Bamberton (open symbols). Abbreviations: s, summer months May-September; w, winter months October-April. In panel C, G1-2 represents growth from size class 1 to 2 for Bamberton and 1 to 3 for Robbers Passage; G2-3 represents growth from size class 2 to 3; and so forth. Error bars represent $95 \%$ confidence intervals. Parameters that were not estimable are shown as zero values.

fecundity or recruitment (Nakaoka 1997, Svensson et al. 2004).

Because adult survival is so important to population growth the adult characteristics of the varnish clam will 

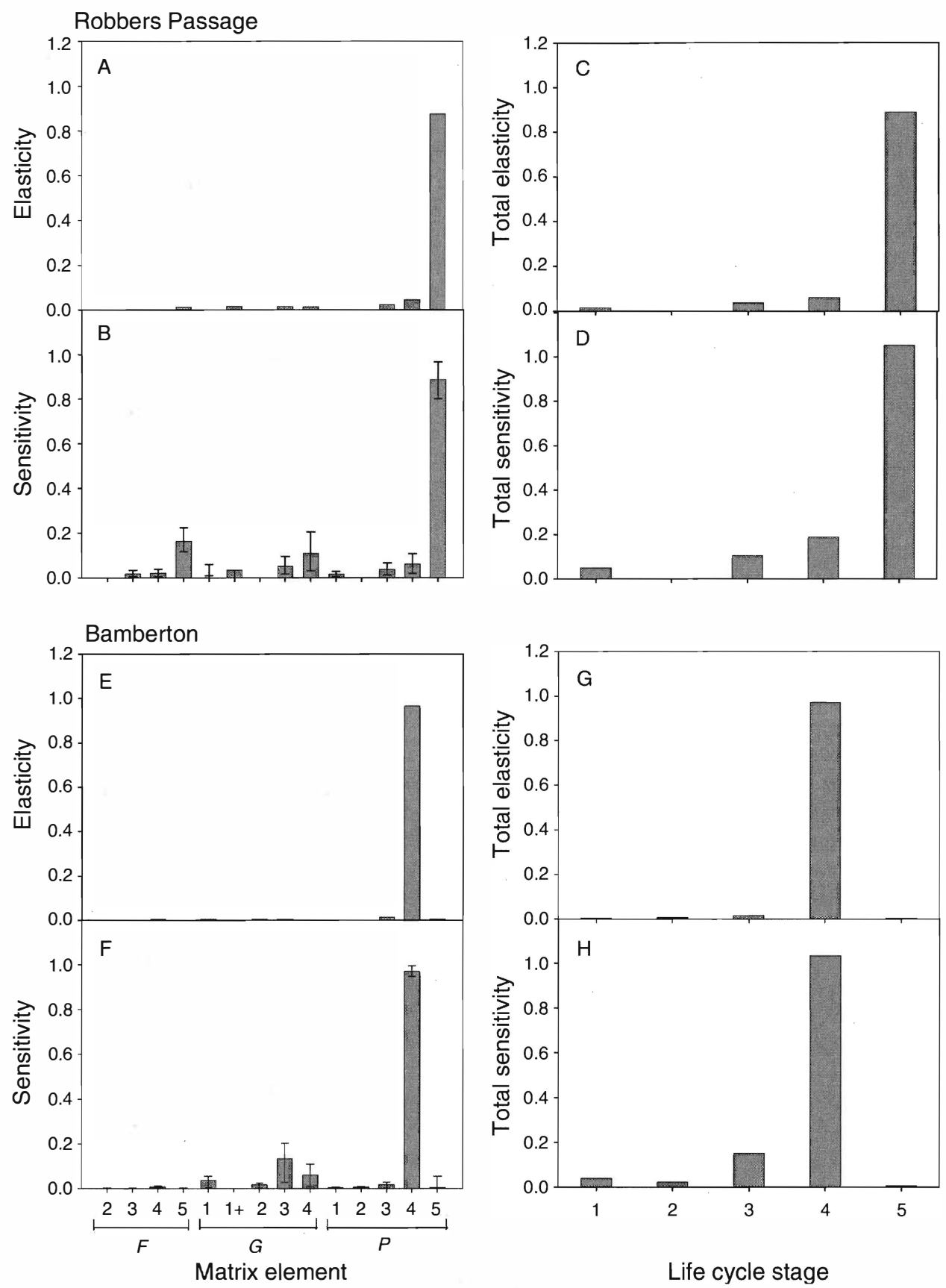

FIG. 3. Matrix element (A, E) elasticity and (B, F) sensitivity, and total size class (C, G) elasticity and (D, H) sensitivity for Robbers Passage (top panels) and Bamberton (bottom panels). $F_{i}$ is the reproductive rate for size class $i, P_{i}$ is the survival rate for size class $i, G 1+$ is the growth rate from size class $1-3$, and $G_{i}$ is the growth rate from size class $i$ to $i+1$.

be the most influential in the species' success. For instance, varnish clam morphology (i.e., thin shell, compressed shape) increases its vulnerability to predation (Dudas et al. 2005), but also increases its burial efficiency (Nel et al. 2001). Similarly, its deeper burial depth decreases the varnish clam's accessibility to predators (Byers 2002, Dudas et al. 2005), while increasing its ability to live high in the intertidal zone, which consequently decreases its exposure to predators that can only feed when submerged (e.g., crabs and flatfish). The influence of adult morphological and behavioral characteristics on survival has likely played a dominant role in the invasion success of the varnish clam in coastal BC.

Growth rates of both populations were negative $(\lambda=$ 0.73 , Robbers Passage; $\lambda=0.84$, Bamberton). Annual population survey data from Robbers Passage are very similar, with annual declines of $24 \%$ and $22 \%$ in 2002 
and 2003, respectively. Declining population growth rates as the invader becomes more established have been observed before (Parker 2000). Based on the life table response experiment, between-site differences in population growth rates are due to the contribution of survival rate differences in $40-50 \mathrm{~mm}$ clams. Interestingly, the largest differences in the transition matrix elements occurred between reproductive contributions $(F)$ of clams that were $\geq 50 \mathrm{~mm}$ (Fig. $4 \mathrm{~A}$ ). Although the difference in reproductive contributions between the sites was twice that of the $40-50 \mathrm{~mm}$ clam survival rates, differences in survival rates contributed the most to population growth rate differences between sites.

Varnish clam populations experience highly variable levels of recruitment, ranging from regular annual recruitment (Bamberton), to relatively low levels of annual recruitment, or episodic pulses of recruitment interspersed with years of no recruitment (Robbers Passage). The ability of bivalves to sustain populations in fluctuating environments even in the face of highly variable recruitment levels has been previously demonstrated in a long-term study of Yoldia notabilis (Nakaoka 1993). This population was maintained by recruitment pulses once every few years that were large enough to cause increases in population size $(\lambda>1)$. Varnish clam recruitment is variable in both Puget Sound (Selleck 2003) and in its home range (Miyawaki and Sekiguchi 2000), and presumably in coastal BC, as well. The varnish clam has a life span of at least six years; therefore populations are likely to be sustainable from occasional years of successful recruitment. For example, if recruitment increased to $3.5 \times 10^{-6}$ and $7 \times$ $10^{-5}$ at Robbers Passage and Bamberton respectively, $\lambda$ becomes $\geq 1$ for both populations. Fluctuating growth transition and survival rates can also increase $\lambda$. Increasing these rates by $38 \%$ and $20 \%$ yielded a $\lambda=1$ for Robbers Passage and Bamberton, respectively.

Variation in both pre-settlement (e.g., larval supply) and post-settlement (e.g., resource competition, predation, physical disturbance) processes cause variation in adult population size (Thorson 1950) and are important in structuring communities (Olaffson et al. 1994). The low sensitivities and elasticities observed here for the reproductive values, $F$ (which also incorporate recruitment in the matrix model), indicate that post-settlement processes are influential for adult population dynamics for Bamberton and Robbers Passage. The relative importance of pre- and post-settlement processes may vary, however, with larval settlement being more influential at lower population and recruitment densities, and post-settlement processes becoming increasingly important at higher population and recruitment densities (Caley et al. 1996, Morgan 2001). Differences in the sensitivity and elasticity values for $F$ between the two populations support this suggestion, with sensitivities and elasticities for Robbers Passage (which experiences low recruitment) being six and 27 times greater than the Bamberton population. This suggests

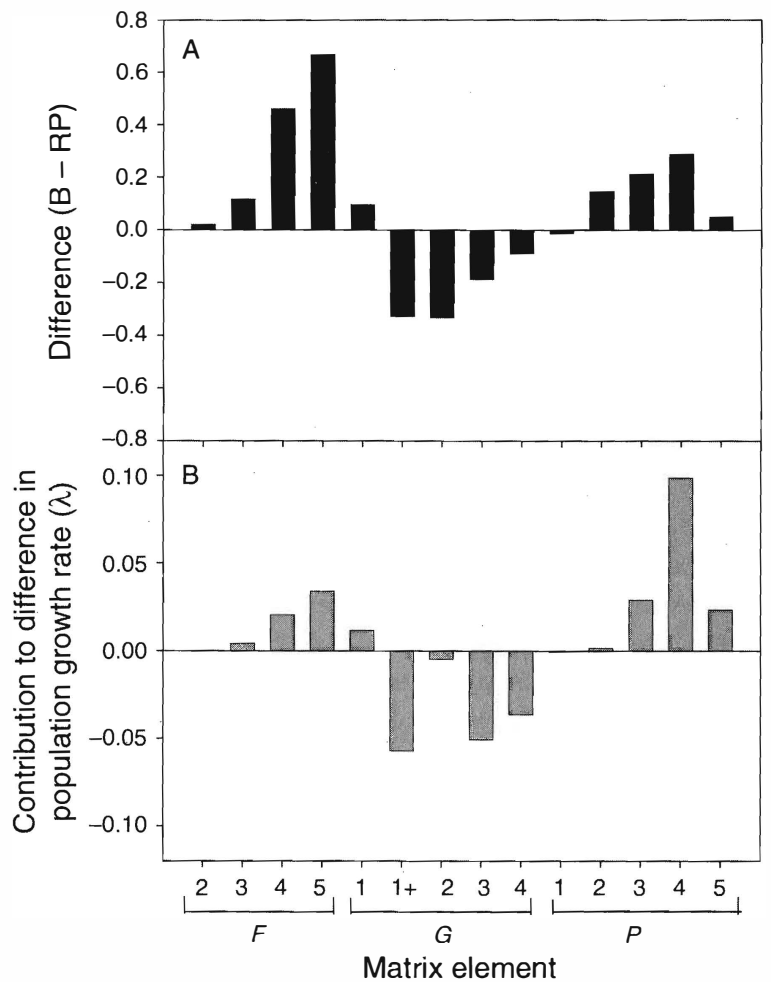

FIG. 4. (A) Matrix element differences between Bamberton and Robbers Passage (B - RP), and (B) their contribution to differences in population growth rate $(\lambda)$. Matrix elements are the same as in Fig. 3.

that the adult population at Robbers Passage will be more sensitive to recruitment variation than the Bamberton population. Accordingly, when recruitment in the matrix model for each population is increased by $33 \%$, the population growth rates $(\lambda)$ increased $7 \%$ for Robbers Passage and $0.2 \%$ for Bamberton. Similarly, population studies of barnacles have shown that sites with low rates of larval settlement also have low adult abundance that varies greatly between years, whereas sites with high larval settlement have both a higher average adult abundance and lower interannual variability in abundance, regardless of differences in settlement (Gaines and Roughgarden 1985).

Field observations support the matrix analysis results, which indicate that post-settlement processes are more influential at Bamberton compared to Robbers Passage. Monthly length-frequency distributions show evidence of higher post-settlement mortality at Bamberton (Dudas 2005). At Bamberton there are a large number of small individuals $(<20 \mathrm{~mm})$, however, they appear to suffer high mortality because few grow through to the larger size classes. Alternatively, at Robbers Passage there are few small clams $(<20 \mathrm{~mm})$ however a pulse of individuals survives and grows through the larger size classes (Dudas 2005), indicating low post-settlement mortality. Similarly, studies from the varnish clam's native range show that where larval supply and 
settlement are high (i.e., similar to Bamberton), postsettlement processes determined adult population characteristics (Sekiguchi et al. 1995).

Based on the relatively small damping ratios, neither population appears to be close to reaching its stable sizeclass structure. Therefore these populations may be influenced by transient dynamics that may differ from asymptotic or long-term behavior at the stable size distribution (Horvitz and Schemske 1995). Transient behavior may influence the accuracy of the matrix model results (e.g., population growth rate, sensitivity), which are based on populations that have reached a stable size distribution.

One drawback of deterministic matrix models is the assumption that vital rates remain constant over time (Caswell 2001). Thus, uncertainty and plasticity in these rates are not accounted for (Miller 2001). Stochasticity can be incorporated into these rates through matrix or element selection (Kaye 2001), thereby allowing vital rates to vary temporally. The results of incorporating stochasticity can vary greatly depending on the choice of probability distribution that is assumed (Nakaoka 1997). Because of the short duration of this study, however, it was not possible to incorporate variation in vital rates. Nevertheless, the observed vital rates do appear to be robust against variation, given the consistently high sensitivities and elasticities observed for the large size classes, even when growth transition and survival rates were allowed to vary. Furthermore, adding variance to reproduction also had little influence on population growth rate estimates.

This study represents one of the first applications of a matrix demographic modeling approach to the investigation of marine invasion dynamics. The observed differences in recruitment, and the corresponding population dynamics, provide evidence of the importance of post-settlement relative to pre-settlement processes, particularly for populations with high recruitment (Bamberton). Despite the differences in growth and reproductive rates between the two sites, adult survival is the most crucial vital rate for population growth at both Robbers Passage and Bamberton. Thus, any process that affects the survival of large clams will therefore influence population growth. Because varnish clams must bury deeply in order to avoid predators (and keep survival rates high), varnish clams are unlikely to establish large populations on beaches with substratum that does not allow deep burial (Byers 2002). Furthermore, harvesting of this species is likely to have a disproportionate impact on its population growth because the clams most likely to be removed (i.e., the largest individuals) are also those that are most crucial to population growth

\section{ACKNOWLEDGMENTS}

This research was supported by NSERC (National Sciences and Engineering Research Council of Canada) Postgraduate Scholarships to S. E. Dudas and an NSERC Discovery Grant to J. F. Dower. We thank the Bamfield Marine Sciences Centre staff for providing research facilities and technical support; Res Altwegg and Jon Schnute for statistical support and advice; and James Mortimor, Megan Foss, Dan Curtis, Tara Brown, Caroline Fox, and Jen Mersereau for field support.

\section{Literature Cited}

Barrett, S. C. H., and B. J. Richardson. 1986. Genetic attributes of invading species. Pages 21-29 in J. T. Burdon, editor. Ecology of biological invasions: an Australian perspective. Cambridge University Press, Cambridge, UK.

Beukema, J. J., P. J. C. Honkoop, and R. Dekker. 1998. Recruitment in Macoma balthica after mild and cold winters and its possible control by egg production and shrimp predation. Hydrobologia 375/376:23-34.

Brousseau, D. J. 1978. Population dynamics of the soft-shell clam Mya arenaria. Marine Biology 50:63-71.

Brousseau, D. J., and J. A. Baglivo. 1982. Estimation of equilibrium settlement rates for benthic marine invertebrates: its application to Mya arenaria (Mollusca: Pelecypoda). Fishery Bulletin 80:642-644.

Brownie, C., J. E. Hines, J. D. Nichols, K. H. Pollock, and J. B Hestbeck. 1993. Capture-recapture studies for multiple strata including non-Markovian transitions. Biometrics 49:11731187.

Buhle, E. R., M. Margolis, and J. L. Ruesink. 2005. Bang for buck: cost-effective control of invasive species with different life histories. Ecological Economics 52:355-366.

Burnham, K. P., and D. R. Anderson. 1998. Model selection and inference: a practical information-theoretic approach. Springer, New York, New York, USA:

Byers, J. E. 2002. Physical habitat attribute mediates biotic resistance to non-indigenous species invasion. Oecologia 130 146-156.

Byers, J. E. 2005. Marine reserves enhance abundance but not competitive impacts of a harvested non-indigenous species. Ecology 86:487-500

Caley, M. J., M. H. Carr, M. A. Hixon, T. P. Hughes, G. P. Jones, and B. A. Menge. 1996. Recruitment and the local dynamics of open marine populations. Annual Review of Ecology and Systematics 27:477-500.

Caswell, H. 2001. Matrix population models: construction, analysis and interpretation. Second edition. Sinauer Associates, Sunderland, Massachusetts, USA.

Crouse, D. T., L. B. Crowder, and H. Caswell. 1987. A stagebased population model for loggerhead sea turtles and implications for conservation. Ecology 68:1412-1423.

Davis, J. L. D., and L. A. Levin. 2002. Importance of prerecruitment life-history stage to population dynamics of the woolly sculpin Clinocottus analis. Marine Ecology Progress Series 234:229-246.

Dudas, S. E. 2005. Invasion dynamics of a non-indigenous bivalve, Nuttallia obscurata, (Reeve 1857), in the Northeast Pacific. Dissertation. University of Victoria, Victoria, British Columbia, Canada.

Dudas, S. E., and J. F. Dower. 2006. Reproductive ecology and dispersal potential of the varnish clam, Nuttallia obscurata, a recent invader in the Northeast Pacific. Marine Ecology Progress Series 320:185-194.

Dudas, S. E., I. J. McGaw, and J. F. Dower. 2005. Selective crab predation on native and introduced bivalves in British Columbia. Journal of Experimental Marine Biology and Ecology 325:8-17.

Ehrlich, P. R. 1986. Which animal will invade? Pages 79-95 in J. A. Drake, editor. Ecology of biological invasions of North America and Hawaii. Springer-Verlag, New York, New York, USA.

Forsyth, R. 1993. Nuttallia obscurata, an introduced bivalve (Psammobiidae) in British Columbia. Vancouver Shell News 14:9-12.

Gaines, S. D., and J. Roughgarden. 1985. Larval settlement rate: a leading determinant of structure in an ecological 
community of the marine intertidal zone. Proceedings of the National Academy of Science (USA) 82:3707-3711.

Gillespie, G., M. Parker, and B. Merilees. 1999. Distribution, abundance, biology and fisheries potential of the exotic varnish clam (Nuttallia obscurata) in British Columbia. Canadian Stock Assessment Secretariat Research Document 99/193:39.

Gotelli, N. J. 1991. Demographic models for Leptogorgia virgulata, a shallow-water Gorgonian. Ecology 72:457-467.

Govindarajulu, P., R. Altwegg, and B. R. Anholt. 2005. Matrix model investigation of invasive species control: bullfrogs on Vancouver Island. Ecological Applications 15:2161-2170.

Grant, C. M., S. H. Hooker, R. C. Babcock, and R. G. Creese. 1998. Synchronous spawning and reproductive incompatibility of two bivalve species: Paphies subtriangulata and Paphies australis. Veliger 41:148-156.

Horvitz, C. C., and D. W. Schemske. 1995. Spatiotemporal variation in demographic transitions of a tropical understory herb: projection matrix analysis. Ecology 65:155-192.

Hughes, T. P. 1990. Recruitment limitation, mortality and population regulation in open systems: a case study. Ecology $71: 12-120$

Kaye, T. N. 2001. Population viability analysis of endangered plant species: an evaluation of stochastic methods and an application to a rare prairie plant. Dissertation. Oregon State University, Corvallis, Oregon, USA.

Lebreton, J. D., K. P. Burnham, and D. R. Anderson. 1992. Modeling survival and testing biological hypotheses using marked animals: a unified approach with case studies. Ecological Monographs 62:67-118.

Levin, L. A., and H. Caswell. 1987. Demographic consequences of larval developmental mode: planktotrophy vs. lecithotrophy in Streblospio benedicti. Ecology 68:1877-1886.

Marco, D. E., and S. A. Paez. 2000. Invasion of Gleditsia triacanthos in Lithraea ternifolia Montane forests of central Argentina. Environmental Management 26:409-419.

Marshall, D. J., D. Semmens, and C. Cook. 2004. Consequences of spawning at low tide: limited gamete dispersal for a rockpool anemone. Marine Ecology Progress Series 266:135142 .

Merilees, B., and G. Gillespie. 1995. Two new exotic clams in Georgia Strait. Discovery 24:143-145.

Miller, T. J. 2001. Matrix-based modeling of blue crab population dynamics with applications to the Chesapeake Bay. Estuaries 24:535-544.

Miyawaki, D., and H. Sekiguchi. 2000. Long-term observations on larval recruitment processes of bivalve assemblages on temperate tidal flats. Benthos Research 55:1-16.

Morgan, S. G. 2001. The larval ecology of marine communities. Pages 159-181 in M. Bertness, S. D. Gaines, and M. E. Hay, editors. Marine community ecology. Sinauer Associates, Sunderland, Massachusetts, USA.

Nakaoka, M. 1993. Yearly variation in recruitment and its effect on population dynamics in Yoldia notabilis (Mollusca: Bivalvia), analysed using projection matrix model. Researches on Population Ecology 35:199-213.
Nakaoka, M. 1997. Demography of the marine bivalve Yoldia notabilis in fluctuating environments: an analysis using a stochastic matrix model. Oikos 79:59-68.

Nel, R., A. McLachlan, and D. P. E. Winter. 2001. The effect of grain size on the burrowing of two Donax species. Journal of Experimental Marine Biology and Ecology 265:219-238.

Neubert, M. G., and H. Caswell. 2000. Demography and dispersal: calculation and sensitivity analysis of invasion speed for structured populations. Ecology 81:1613-1628.

Olaffson, E. B., C. H. Peterson, and W. G. Ambrose. 1994. Does recruitment limitation structure populations and communities of macro-invertebrates in marine soft-sediments: the relative significance of pre- and post-settlement processes. Oceanography and Marine Biology: An Annual Review 32:65-109.

Parker, I. M. 2000. Invasion dynamics of Cytisus scoparius: a matrix model approach. Ecological Applications 10:726-743.

Pascual, M., and H. Caswell. 1992. The dynamics of a sizeclassified benthic population with reproductive subsidy. Theoretical Population Biology 39:129-147.

Pollock, K. H., J. D. Nichols, C. Brownie, and J. E. Hines. 1990. Statistical inference for capture-recapture experiments. Wildlife Monographs 107:1-97.

Pradel, R., C. M. A. Wintrebert, and O. Gimenez. 2003. A proposal for a goodness-of-fit test to the Arnason-Schwarz multistate capture-recapture model. Biometrics 59:43-53.

Ruesink, J. L. 2003. Hindcasting invasion impact based on species demography. Page 10 in Proceedings of the Third International Conference on Marine Bioinvasions, La Jolla, California, 16-19 March, 2003. MIT Sea Grant College Program, Cambridge, Massachusetts, USA.

Sekiguchi, H., M. Uchida, and A. Sakai. 1995. Post-settlement processes determining the features of bivalve assemblages in tidal flats. Benthos Research 49:1-14.

Selleck, J. R. 2003. Comparative reproductive events of the invasive varnish clam, Nuttallia obscurata, and the fisheries littleneck clam, Venerupis philippinarum. Thesis. Western Washington University, Bellingham, Washington, USA.

Shea, K., and D. Kelly. 1998. Estimating biocontrol agent impact with matrix models: Carduus nutans in New Zealand. Ecological Applications 8:824-832.

Svensson, C. J., S. R. Jenkins, S. J. Hawkins, A. A. Myers, P. Range, J. Paula, R. M. O'Riordan, and P. Aberg. 2004. Models of open populations with space-limited recruitment in stochastic environments: relative importance of recruitment and survival in populations of Semibalanus balanoides. Marine Ecology Progress Series 275:185-197.

Thorson, G. 1950. Reproductive and larval ecology of marine bottom invertebrates. Biological Reviews 25:1-45.

White, G. C., and K. P. Burnham. 1999. Program MARK: survival estimation from populations of marked animals. Bird Study 46:S120-139.

Wonham, M. J., and J. T. Carlton. 2005. Trends in marine biological invasions at local and regional scales: the Northeast Pacific Ocean as a model system. Biological Invasions 7:369-392.

\section{APPENDIX}

Additional information on varnish clam population structure and fecundity, transition matrices, and predicted size-class abundances based on fixed and variable recruitment at both sites (Ecological Archives E088-124-A1). 